In Cres. Vol. $3 N^{\circ} 1:$ pp. 41-70, 2012

\title{
LA PLANIFICACIÓN FISCAL INTERNACIONAL Y SU RELACIÓN CON LOS PRECIOS DE TRANSFERENCIA, EN EL PERÚ*
}

\author{
THE INTERNATIONAL TAX PLANNING \\ AND ITS RELATION WITH THE \\ TRANSFER PRICES IN PERÚ
}

Javier Leopoldo Ulloa Siccha ${ }^{1}$

\section{RESUMEN}

La internacionalización económica ha incrementado el temor de las administraciones tributarias de los diferentes Estados sobre los riesgos de deslocalización de rentas. Uno de los mecanismos que utilizan las empresas (principalmente multinacionales) como mecanismos de reducción de la carga tributaria consiste en la utilización de los precios de transferencia como mecanismos de traslación de rentas y beneficios entre las diferentes partes del grupo multinacional y, en consecuencia, entre las diferentes jurisdicciones tributarias.

Desde la óptica fiscal los precios de transferencia adquieren significativa importancia en la actualidad, debido a la intensificación del tráfico internacional y al hecho de que gran número de las transacciones nacionales e internacionales se realizan al interior de los grupos empresariales vinculados; según la Organización de Naciones Unidas más del 60\% del comercio transnacional y nacional se realiza entre empresas vinculadas.

El tema de la planificación fiscal dentro del derecho tributario tiene suma relevancia, ya que no sólo se limita al ámbito económico internacional, sino a todo un análisis exhaustivo, por el cual las empresas buscan reducir la carga tributaria. Ello implica tener conocimiento sobre las normas tributarias aplicables, estrategias jurídicamente permitidas y que no ocasionen un perjuicio económico a la administración. Si bien la planificación fiscal internacional se basa en la libertad económica, ésta tiene sus límites, como son: la subcapitalización, gastos procedentes de paraísos fiscales y el valor de mercado. Si bien el contribuyente apunta a reducir su carga tributaria, ello no implica que todo ahorro fiscal configure una evasión o una elusión ilícita.

* Recibido: 24 de enero del 2012; aceptado: 14 de junio del 2012.

1 Contador Público. Maestro en Contabilidad, Mención: Finanzas. Docente de la Universidad Nacional de Trujillo, Facultad de Ciencias Económicas, Escuela de Contabilidad y Finanzas. 
La progresiva internacionalización de las economías lleva a plantear la necesidad de realizar una planificación fiscal internacional, con el objetivo de minimizar la carga fiscal, la cual incide sobre las inversiones o rentas procedentes de diferentes estados.

El rol de la planificación fiscal internacional consiste en buscar la mejor estructura para desarrollarse de manera eficiente; es decir, debe tener en cuenta, los siguientes aspectos: seguridad jurídica de la operación planteada, la incertidumbre de cambios legislativos, la flexibilidad para reorganizar la estructura empresarial, la movilidad de los recursos empleados, el diferimiento en el pago de los tributos, la carga fiscal conjunta y la máxima rentabilidad.

La planificación fiscal internacional basada en la economía de opción requiere de una estrategia efectiva y eficiente para maximizar beneficios. Para ello, acude a las normas tributarias aplicables para obtener la seguridad jurídica en las operaciones comerciales; sin embargo, debe evitar el abuso de estrategias que de manera encubierta y simulada, configuren operaciones entre vinculadas con valores inferiores o mayores, cuya única finalidad sea aminorar la carga fiscal.

PALABRAS ClAVE: Planificación Fiscal Internacional, Precios de Transferencia en el Perú.

\section{ABSTRACT}

The economic internationalization has incremented Tax Tributaries's fear of the different states about the risk of the tax deslocalization. One of the mechanisms that the companies use ( multinational companies) as mechanisms of reduction of the tax burden consists on using the transfer prices as mechanisms of transfering profits and rents among the different parts of the multinational group and consequently among the different tax jurisdictions.

At present, from the tax perspective, the transfer prices acquire significant importance, due to the intensification of the international traffic and also because of a great deal of national and international transactions take place into the linked enterprise groups. According to the United Nations, over $60 \%$ of the national and international trade is carried out among linked enterprises.

The tax planning within the tax law is relevant, since it is not only limited to the international matter but, to the whole analysis, by this, the companies try to reduce its tax burden. It implies having knowledge on the tax regulations. strategies that be legally allowed and that do not cause a cost-reducing damage to administration, strategies. Even though the fiscal international planning is based on the cost-reducing freedom, this has its limits; Undercapitalization, appropriate expenses of tax havens and the value of market. Even though the contributor reduces the tax burden, it does not imply that all tax saving be a tax evasion.

The progressive internationalization of economies leads to need to accomplish a tax international planning, in order to minimize the tax burden, which affects on investments or on appropriate incomes of different states.

The role of the tax international planning involves looking for the best structure to develop in an efficient way; That is, it should take in account, the following aspects: legal certainty of 
the operation, the uncertainty of legislative changes, the flexibility to reorganize the entrepreneurial structure, the mobility of the used resources, the deferring in the payment of the tax, the tax burden and the maximum profitability.

The international tax planification based on economy of option requires of an effective and efficient strategy to maximize profits. In order to get it, it relies on the applicable tributary standards to obtain the juridical certainty in the commercial operations; however, it must avoid the abuse of strategies that in a simulated and covered way set up operations linked with lower and upper values, whose only purpose be to decrease the tax burden.

KEY WORDS: International Tax Planning, Transfer Prices in Peru.

\section{INTRODUCCIÓN}

El tema de la planificación fiscal dentro del derecho tributario ha tomado suma relevancia, ya que no sólo se limita al ámbito económico internacional, sino a todo un análisis exhaustivo, por el cual las empresas buscan reducir la carga tributaria. Ello implica tener conocimiento sobre las normas tributarias aplicables, estrategias jurídicamente permitidas y que no ocasionen un perjuicio económico a la administración. Si bien la planificación fiscal internacional se basa en la libertad económica, ésta tiene sus límites, como son: la subcapitalización, gastos procedentes de paraísos fiscales y el valor de mercado. Si bien el contribuyente apunta a reducir su carga tributaria, ello no implica que todo ahorro fiscal configure una evasión o una elusión ilícita.

La progresiva internacionalización de las economías lleva a plantear la necesidad de realizar una planificación fiscal internacional, con el objetivo de minimizar la carga fiscal, la cual incide sobre las inversiones o rentas procedentes de diferentes estados.

Toda planificación fiscal no sólo debe conducir a un resultado fiscal mínimo, sino que debe tenerse en cuenta otros muchos aspectos, como la seguridad jurídica de la operativa planteada, la incertidumbre de cambios legislativos, la flexibilidad para reorganizar la estructura empresarial, la movilidad de los recursos empleados, el diferimiento en el pago de los impuestos, la carga fiscal conjunta, y en definitiva, la máxima rentabilidad.

Según APAZA (2007: 45) “(...) la planificación fiscal, al ser una actividad perfectamente legítima, estimulable y a menudo necesaria, tiene como finalidad primordial la optimización del costo. En ese sentido, las ventajas de una adecuada planificación fiscal son:

a) Permite la optimización del costo derivado del cumplimiento de las obligaciones tributarias, derivado del pago del tributo, así como la carga de los 
cumplimientos, de pago mismo, tales como el costo de la efectivización del pago o la devolución del impuesto pagado o indebido.

b) Incentiva a la competencia fiscal por parte de los Estados, lo cual genera la creación de disposiciones de mayor ventaja fiscal para el sector privado, atrayendo inversiones y sobre todo ofreciéndoles seguridad jurídica a las transacciones.

c) Brinda la posibilidad de diferir el pago de impuestos a un futuro, lo que conduce a un ahorro financiero, que bien planificado puede llegar a una progresividad menor en los impuestos directos al poder distribuir los rendimientos".

Para un estudio de precios de transferencia se necesita evaluar la información financiera y descriptiva de las operaciones que las empresas realicen con partes relacionadas residentes en el extranjero. La documentación necesaria para analizar estas operaciones se engloba en un estudio que se divide en dos partes: Análisis Funcional-Descriptivo y Análisis Económico-Financiero. En el Perú se ha introducido este principio, llamado principio del valor de mercado, que se encuentra plasmado en el numeral 4 del artículo $32^{\circ}$ de la Ley del Impuesto a la Renta, aprobado por Decreto Supremo $N^{\circ} 054-99-E F$, que establece que en los casos de ventas, aportes de bienes y demás transferencias de propiedad a cualquier título, el valor asignado a los bienes para efectos del impuesto a la renta, será el valor del mercado. Si el valor difiere del valor del mercado, la SUNAT procederá a ajustarlo tanto para el adquirente como para el oferente. Sin embargo, esta disposición en la práctica resulta ser ineficiente, puesto que para llegar a los estándares establecidos por las fuerzas del mercado se requiere no sólo un análisis tributario, sino macroeconómico de la operación.

Según SANMARCo (2008:32) “(...) el estudio de los precios de transferencia implica la necesidad de contar con una metodología que permita establecer los valores entre partes vinculadas y que en sus operaciones guarden un patrón de normalidad tributariamente aceptable". Las administraciones fiscales no deben asumir de pleno que las empresas vinculadas buscan manipular sus utilidades; los precios de transferencia no deben ser confundidos con problemas de evasión o elusión fiscal.

SPITZ (2006: 62), manifiesta “(...) la primera jurisdicción fiscal que promulgó una norma interna para combatir la manipulación de los precios de transferencia fue el Reino Unido en 1915, a través de la Ley de Finanzas de 1915, se establecía que en el supuesto de que una entidad no residente llevara a cabo actividades económicas con una empresa residente en el Reino Unido y la empresa no residente tuviera una estrecha conexión y ejerciera un control sustancial 
sobre la empresa residente en la jurisdicción fiscal inglesa; si, como consecuencia de esto, el negocio realizado entre las dos producía en la empresa residente un beneficio menor que el que se habría esperado, la entidad no residente debía tributar en el Reino Unido como agente de la empresa residente por los beneficios desviados hacia ella en la operación vinculada".

Por esta misma época, encontramos en Argentina el primer antecedente de una regulación sobre precios de transferencia en Latinoamérica (artículo 20 de la Ley 11682 de 1932). Otros países latinoamericanos demorarían mucho más en promulgar una regulación sobre la materia: México, en 1992; Brasil, en 1996; y Colombia, en el 2002.

En 1968, Estados Unidos sería el primer país en promulgar una reglamentación detallada desarrollando los métodos que debían ser utilizados en su criterio para la determinación de unos precios de transferencia correctos para efectos fiscales.

Dos hechos marcaron en 1994 el desarrollo del tema de precios de transferencia en México: el Tratado de Libre Comercio de América del Norte ( TLCAN) y su ingreso a la OCDE, lo que originó la celebración de múltiples convenios para evitar la doble tributación. En 1995, la ley mexicana sobre precios de transferencia empezó a evolucionar significativamente, introduciendo dos importantes modificaciones en el ordenamiento tributario en materia de precios de transferencia con un especial énfasis en la industria maquiladora, la cual estaba en pleno desarrollo en virtud del TLCAN.

Sin embargo, en México, sólo hasta 1997 se estableció que todo contribuyente, ya no sólo maquiladoras, que celebrara operaciones entre partes relacionadas, tenía la obligación de demostrar que los precios utilizados eran comparables entre partes independientes. México fue el primer país de Latinoamérica en adoptar el régimen de precios de transferencia acordes con los principios y pautas de la OCDE.

Finalmente, por esta época también en Brasil se introdujo en forma clara el concepto de precios de transferencia en el impuesto a la renta para las personas jurídicas, mediante la Ley 9.43027 de diciembre 1996, específicamente regulando: "los precios de transferencia de operaciones de importación y exportación entre empresas vinculadas, la remesa de intereses entre éstas y las operaciones realizadas entre empresas establecidas en países con tributación favorecida "paraísos fiscales".

A partir del 01.01.04, existe en el Perú la obligación sustancial de observar el principio de libre concurrencia (Arm's Length) en la realización de ope- 
raciones entre entidades vinculadas y/o realizadas desde, hacia o a través de países o territorios considerados como de nula o baja imposición para propósitos tributarios, según Decreto Legislativo $\mathrm{N}^{\circ} 945$.

$\mathrm{Al}$ respecto, desde el año antes indicado hasta la actualidad la legislación fiscal peruana que regula dicha obligación ha sido objeto de importantes modificaciones, dirigidas tanto a garantizar la protección de la base gravable que corresponde a la jurisdicción fiscal nacional, como también a prevenir eventuales escenarios de doble imposición tributaria.

No obstante, pese a la regulación específica dada en el año 2001, recién es en el año 2006 que se reglamentan los requisitos de documentación de los Precios de Transferencia (PT), dando inicio al cumplimiento de obligaciones formales consistentes, tanto en contar con el Estudio de Precios de Transferencia (EPT), como también en presentar la respectiva Declaración Jurada Informativa de Precios de Transferencia (DJIPT).

Si todos los países tuvieran la misma estructura fiscal, entonces los precios de transferencia se podrían fijar independientemente de los impuestos. Sin embargo, hay países que tienen altos impuestos (como Estados Unidos) y otros que tienen bajos impuestos (como las Islas Caimán). El efecto es que las compañías multinacionales pueden utilizar los precios de transferencia para trasladar sus costos a países de altos impuestos y trasladar sus ingresos a países de bajos impuestos.

Serán considerados como fuentes de interpretación las guías sobre precios de transferencia para empresas multinacionales y administraciones fiscales aprobadas por el Consejo de la organización para la Cooperación y el Desarrollo (OCDE), en tanto las mismas no se opongan a las disposiciones aprobadas por la Ley del Impuesto a la Renta.

La progresiva internacionalización de las economías lleva a plantear la necesidad de realizar una planificación fiscal internacional con el objetivo de minimizar la carga fiscal, la cual incide sobre las inversiones o rentas procedentes de diferentes estados. Acorde con SANMARCo (2008: 36), la Planificación Fiscal Internacional ya no es un fin, sino un medio para organizar y rentabilizar una inversión empresarial, sobre la cual, a pesar de tener suma relevancia, se ha escrito muy poco y de forma genérica, pensándose sólo en operaciones con paraísos fiscales.

Según GARCíA (2009: 124) "La planificación fiscal internacional persigue minimizar dentro de la más estricta legalidad, la carga tributaria derivada del 
ejercicio de una actividad económica empresarial o de la tenencia de un patrimonio mediante la acción de la elección de la acción más eficiente entre todas las alternativas legales posibles, eligiendo por ello la jurisdicción con una normativa jurídico-tributaria más beneficiosa".

Según APAZA M. (2007: 48), “(...) la Planificación Fiscal Internacional no es un instituto jurídico sino todo un sistema complejo coordinado de situaciones orientadas a la creación de relaciones y situaciones jurídicas con la finalidad de optimizar la carga tributaria”. Siguiendo esta línea, la planificación económica comportará el problema de elegir la estructura empresarial que mejor se adapte al tipo de actividad de la empresa, y sobre todo al país donde se quiera realizar la actividad. El rol de la planificación fiscal internacional consiste en buscar la mejor estructura para desarrollarse de manera eficiente y productiva, en una economía mundial. Según BARNADAS (2009: 104): “Toda Planificación no solo debe conducir a un resultado fiscal mínimo sino que debe tenerse en cuenta otros muchos aspectos como son la seguridad jurídica de la operativa planteada, la incertidumbre de cambios legislativos, la flexibilidad para reorganizar la estructura empresarial, la movilidad de los recursos empleados, el diferimiento en el pago de los impuestos, la carga fiscal conjunta, y en definitiva máxima rentabilidad".

Según AdONNino (2008: 76), “(...) la elusión es distinta a la economía de impuesto por un lado y de la evasión fiscal por otro. Se puede definir como elusivos aquellos comportamientos realizados intencionalmente con el solo fin de no configurar el hecho típico que el legislador ha considerado como constitutivo de la obligación tributaria, pero que le permiten conseguir un resultado económico análogo, o suficientemente fungible, y esto al solo o principal objeto de atenuar o anular la pretensión fiscal".

En nuestro país, las dudas e inquietudes surgen a razón del D. Leg. $\mathrm{N}^{\circ}$ 945, que entre otros temas, adecuó a los parámetros internacionales la normativa de Precios de Transferencia que ya había sido recogida mediante la Ley 27356 (18/10/2000) y su Reglamento, el D.S. N ${ }^{\circ} 045-2001-E F$, cuyas aplicaciones eran de aplicación a partir del ejercicio 2004.

SPITZ (2006: 79) hace la siguiente afirmación: “(...) con dicha regulación se crearon una serie de obligaciones que las empresas vinculadas debían cumplir para sustentar los precios fijados en sus transacciones tales como llevar un estudio técnico, contar con determinada documentación e información, aplicar determinados métodos de valoración a efectos de fijar los precios de transferencia". 
GARCÍA (2009: 102) sostiene: “(...) se habla que el traslado encubierto de las utilidades o pérdidas entre empresas de un mismo grupo económico con la finalidad de tener un menor gasto tributario, ha sido la razón fundamental para que se establezcan las normas que regulan los precios de transferencia en el mundo".

Sobre el particular, CARRIÓN (2005: 86) señala que, “(...) existen cuatro elementos que caracterizan tal traslado encubierto de utilidades o pérdidas.

El primero se refiere a que dicha transferencia no operará directamente sobre los beneficios, sino indirectamente a través de transacciones previas a la obtención formal de la utilidad; es decir, lo encubierto no será la utilidad en sí, sino el encubrimiento será respecto a la determinación de tal utilidad (sobrevalorar costos, subvaluar gastos, entre otros).

El segundo elemento será la obtención de ventajas anormales del contratante con quien realiza la operación; así, los contratantes aceptarán pagar más ante un abultamiento de costos y gastos, o aceptarán recibir menos ante la reducción de ingresos.

El tercer elemento será la participación de una entidad vinculada con quien se realiza la transferencia. Tal nexo de vinculación indicará la pertenencia de

RESUMEN DE REGULACIONES DE PRECIOS

DE TRANSFERENCIA $(*)$

\begin{tabular}{lccccc}
\hline \multicolumn{1}{c}{ País } & $\begin{array}{c}\text { Reglas } \\
\text { desde }\end{array}$ & Estudio & $\begin{array}{c}\text { Arm's } \\
\text { Length }\end{array}$ & $\begin{array}{c}\text { Actividad } \\
\text { Auditoras }\end{array}$ & País \\
\hline Argentina & 1988 & $\checkmark$ & $\checkmark$ & Alta & x \\
Brasil & 1998 & X & x & Alta & Limitado \\
Canadá & 1999 & $\checkmark$ & $\checkmark$ & Alta & $\checkmark$ \\
Chile & 1997 & x & $\checkmark$ & Baja & x \\
Colombia & 2004 & $\checkmark$ & $\checkmark$ & Muy probable & $\checkmark$ \\
Ecuador & 2005 & $\checkmark$ & $\checkmark$ & Baja & x \\
EE.UU. & 1968 & $\checkmark$ & $\checkmark$ & Alta & $\checkmark$ \\
México & 1997 & $\checkmark$ & $\checkmark$ & Alta & $\checkmark$ \\
Perú & 2001 & $\checkmark$ & $\checkmark$ & Probable & $\checkmark$ \\
Uruguay & 2007 & $\mathrm{x}$ & $\checkmark$ & Baja & $\mathrm{x}$ \\
Venezuela & 1999 & $\checkmark$ & $\checkmark$ & Activa & $\checkmark$ \\
\hline
\end{tabular}

* Tomado de http://ifaperu.org/docs/curiel_27.01.09.pdf 
ambos operadores a una misma entidad empresarial, facilitando con ello el traslado encubierto de beneficios o pérdidas entre los integrantes de dicha entidad.

Por último, un cuarto elemento referido a la presencia de la operación es una u otra jurisdicción tributaria (en el caso de transferencias internacionales), dicha situación busca aprovechar diferentes regímenes tributarios de los países implicados".

El presente estudio se justifica, por cuanto el tema de la planificación fiscal dentro del derecho tributario ha tomado suma relevancia, ya que no sólo se limita al ámbito económico internacional, sino a todo un análisis exhaustivo, por el cual las empresas buscan reducir la carga tributaria. Ello implica tener conocimiento sobre las normas tributarias aplicables. Estrategias jurídicamente permitidas y que no ocasionen un perjuicio económico a la administración. Si bien la planificación fiscal internacional se basa en la libertad económica, ésta tiene sus límites, como son: la subcapitalización, gastos procedentes de paraísos fiscales y el valor de mercado. Si bien el contribuyente apunta a reducir su carga tributaria, ello no implica que todo ahorro fiscal configure una evasión o una elusión ilícita.

La reforma tributaria introdujo en el país esta práctica que tendrá un gran impacto sobre la planeación empresarial de las organizaciones internacionales.

Un tema novedoso en el país, tanto en términos conceptuales como prácticos, son los precios de transferencia. Este instrumento combate el fraude y la evasión al hacer más transparentes las operaciones de compra o cesión de bienes y servicios entre empresas económicamente vinculadas (capital, control y dirección).

La reforma tributaria en diciembre pasado a través del D. Leg N ${ }^{\circ} 945(05-$ 12-2004) se ha incluido el artículo 32-A, cuya aplicación se encuentra vigente a partir del ejercido gravable 2005.

La obligación de ceñirse al valor de mercado en la determinación del impuesto a la renta, implica para los contribuyentes un proceso de aprendizaje de una regulación compleja y poco clara.

La implantación de estas reglas es de particular importancia para la administración tributaria, por lo que debería ser esta la principal interesada en facilitar cumplimiento dictando reglas claras que simplifiquen la actividad de los contribuyentes.

PROBLEMA

¿Cómo la planificación fiscal internacional incide en la aplicación de los precios de transferencia en el Perú, y el incremento de la recaudación fiscal? 


\section{OBJETIVOS}

\section{General}

Determinar la incidencia de los mecanismos de control y fiscalización en las empresas que aplican precios de transferencia, incrementando la recaudación fiscal.

\section{Específicos}

1. Analizar la realidad de los países más representativos de la economía mundial que aplican los precios de transferencia.

2. Analizar el actual sistema de precio de transferencia que se aplica en nuestro país.

3. Describir el procedimiento del cálculo de los precios de transferencia entre empresas vinculadas.

\section{HIPÓTESIS}

La planificación fiscal internacional incide favorablemente en la aplicación de los precios de transferencia, mejorando la recaudación fiscal en el Perú.

\section{MATERIAL Y MÉTODOS}

\section{MATERIAL}

\section{Población}

Según la información reportada a la SUNAT: 48 empresas de los diversos sectores económicos, correspondiente al ejercicio económico 2011.

\section{Muestra}

Del total de la población, de manera selectiva se tomó una muestra de 12 empresas, la misma que representa el $25 \%$ de la población.

FóRMULA

$$
n=\frac{p x q}{\frac{E^{2}}{Z^{2}}+\frac{p x q}{N}}
$$

Donde:

$\mathrm{n}=$ Tamaño de la muestra.

$\mathrm{Z}=$ Desviación estándar (para intervalo de confianza de 95.55\%) es 1.96. 
$\mathrm{p}=$ Proporción de la población que posee las características cuando " $\mathrm{n}$ " se conoce tal proporción se asume que " $p$ " es 50.

$\mathrm{q}=\mathrm{p}-1$.

$\mathrm{E}=$ Margen de error 5 .

$\mathrm{N}=$ Tamaño de la población.

De este modo y reemplazando valores, obtendremos el tamaño de la muestra:

$$
\begin{gathered}
n=\frac{50 \times 49}{\frac{25}{3.84}+\frac{50 \times 49}{48}} \\
n=\frac{2450}{6.51+51.04} \\
\mathrm{n}=42.57 \\
\mathrm{n} \approx 43
\end{gathered}
$$

\section{CARACTERÍSTICAS DE LA MUESTRA}

- Representativa: debido a que el número de unidades de análisis trabajadas en la muestra (12) es acorde al tamaño de la población, obtenida luego de aplicar la fórmula para definir el tamaño de la muestra. Por este motivo la muestra es representativa de la población.

- Válida: el tamaño de la muestra (43) está relacionada con los objetivos del estudio y las características de la población.

- Confiable: la muestra es confiable porque la cantidad de unidades de análisis tomadas para la muestra (12) es proporcional con el número de unidades de análisis tomadas para la población.

\section{TIPO DE MUESTREO}

- Bietápica: porque para la entrevista, se ha utilizado el muestreo no probabilístico por expertos; es decir, que de toda la población, no todos la que la conforman han tenido la posibilidad de ser elegidos de muestra para la presente investigación; mientras que para la recopilación documental se ha utilizado el muestreo probabilístico aleatorio; es decir, que de toda la población todos la que la conforman han tenido la posibilidad de ser elegidas de muestra para la presente investigación. 
TIPO DE INVESTIGACIÓN

- Por su finalidad

La presente investigación es aplicada; por tanto, es de aplicación inmediata al existir brevedad en su aplicación. En este tipo de investigación se busca la aplicación o utilización de los conocimientos que se adquieren, para el enriquecimiento del acervo cultural y científico.

- Por su profundidad

La presente investigación es descriptivo-explicativa porque en ella se ha descrito y analizado las variables de la referida investigación, y además se ha determinado los resultados de aplicar uno u otro criterio técnico referido a la aplicación de precios de transferencia.

\section{MÉTODOS Y TÉCNICAS DE INVESTIGACIÓN}

- Métodos de investigación

MÉTODO INDUCTIVO - DEDUCTIVO

Método utilizado tanto en la recolección información, como en la elaboración del marco teórico al establecerse las categorías económicas, tributarias y financieras desde lo general a lo particular, tomando como esencia la normatividad legal y tributaria.

MÉTODO ESTADÍSTICO

Método utilizado desde el momento en que se recogió la información cuantitativa y cualitativa de la presente investigación, así como cuando se trabajó con la población y la determinación de la muestra.

- Técnicas de recopilación, procedimientos y análisis de datos

Para llevar a cabo las acciones de recopilación de información, se aplicaron las siguientes técnicas:

a) Análisis documental.

b) Indagación y encuesta.

c) Conciliación de datos.

d) Tabulación de cuadros con cantidades y porcentajes.

e) Comprensión de gráficos. 


\section{RESULTADOS}

En el desarrollo de casos, sólo se realiza el enfoque de la metodología de su cálculo, debiendo los contribuyentes adicionalmente contar con la documentación y cumplir con los requisitos del contenido del Estudio Técnico de Precios de Transferencia, sin tener en cuenta los montos para la presentación de la Declaración Jurada y de contar con el Estudio Técnico de Precios de Transferencia establecido por la R.S. No $167-2006 /$ SUNAT modificado por la R.S. No 008-2007/SUNAT.

\section{REGLA DEL MEJOR MÉTODO - EN GENERAL}

Para aplicar el mejor método de Precios de Transferencia, se considera el siguiente orden:

1. Precio Comparable no Controlado (CUP).

2. Precio de Reventa o Bien Costo Adicionado C + .

3. Partición de Utilidades o Margen Neto Transaccional (MNT).

\begin{tabular}{ll} 
Tipos de Transacción & Método posible \\
\hline Manufactura de productos Venta de productos & CUP, C + , Partición de Utilidad \\
Provisión de servicios & $\begin{array}{l}\text { CUP, Precio de Reventa. } \\
\text { Partición de Utilidades, MNT. }\end{array}$ \\
Financiero (préstamos, depósitos, garantías) & CUP, C + MNT. \\
Transferencia de Intangibles (tecnología, & CUP, Partición de Utilidades, MNT, \\
marcas, Know-how) & CUP, C + (Costo adicionado).
\end{tabular}

\section{MÉTODO DE PRECIO COMPARABLE NO CONTROLADO - MPC}

El CUP es el primero de los métodos proporcionados por la legislación peruana en materia de precios de transferencia, y la determinación que utiliza dicho método para saber si dos o más empresas están operando a valores de mercado en sus transacciones con partes relacionadas se analiza en los casos prácticos.

El Método de Precio Comparable no Controlado señala lo siguiente:

"Consiste en considerar el precio o el monto de las contraprestaciones que se hubieran pactado con o entre partes independientes en operaciones comparables". 
La Ley del Impuesto a la Renta no aporta elementos adicionales para la aplicación y determinación del CUP. Sin embargo, la Organización para la Cooperación y el Desarrollo Económico (OCDE), en su Guía de Precios de Transferencia, ofrece elementos adicionales y complementarios. De conformidad con dichas guías, y de acuerdo a la práctica generalizada de precios de transferencia, este método tiene dos maneras básicas de aplicación:

1. En primer lugar, se puede utilizar al comparar el precio cargado por la transferencia de bienes o servicios entre partes vinculadas con una transacción similar llevada a cabo con una entidad no vinculada bajo circunstancias similares; es decir, si la empresa analizada vende, por ejemplo, computadoras personales a una empresa vinculada, y además vende la misma computadora personal a una empresa no vinculada, en fechas similares, bajo circunstancias análogas, entonces se pueden comparar los precios a los que dicha empresa vende el producto tanto a su parte relacionada, como a la empresa no vinculada.

De conformidad con el principio Arm's Length, dichos precios deberían ser muy similares en el caso en que las condiciones contractuales pactadas, tanto con las partes vinculadas como con las no vinculadas, no llegaran a ser diferentes en un grado tal que afecten la determinación del precio.

2. La segunda forma de aplicar este método puede ser mediante la comparación del precio pactado entre dos o más empresas vinculadas en el intercambio de un producto, con un precio público competitivo. Es decir, si el producto intercambiado entre las empresas vinculada, donde ellas determinan el precio en torno a una negociación privada, es a la vez cotizado en un mercado público, donde los precios se forman por muchos agentes participantes en dicho mercado, entonces se puede establecer una comparación entre el precio pactado entre las dos partes relacionadas con el precio público en fechas similares.

Si los precios pactados entre las entidades vinculadas son similares a los precios cotizados en un mercado activo (público competitivo), entonces se considera que dichos precios entre partes vinculadas, están pactados a valores de mercado.

Si existiera alguna diferencia entre ambos precios, esto podría indicar que las condiciones de las relaciones comerciales y financieras de las empresas vin- 
culadas no están sobre una base Arm's Length, y que el precio de la transacción controlada debe ser sustituido por el precio que se pactó en la transacción no controlada.

De acuerdo con los lineamientos de la Organización para la Cooperación y el Desarrollo Económico, en materia de precios de transferencia, una transacción no controlada se puede comparar con alguna otra transacción controlada, siempre y cuando:

1. Ninguna de las diferencias entre las transacciones que se están comparando (en caso de existir) deben afectar «materialmente la calidad de la comparación».

2. En caso de existir dichas diferencias, se debe tomar en cuenta que se pueden realizar ajustes razonables para eliminar las diferencias entre los precios que se están comparando.

Asimismo, dichas guías establecen que cuando es posible encontrar transacciones comparables no controladas, el CUP es la forma más directa y confiable para saber si una empresa está o no cumpliendo con el principio Arm's Length. En consecuencia, en esos casos el CUP es preferible sobre todos los demás métodos.

\section{MÉTODO SEGÚN LA LEY DEL IMPUESTO A LA RENTA EN EL PERÚ}

El numeral 1 del inciso e) del Art. 32-A de la Ley del Impuesto a la Renta señala que el método del precio comparable no controlado consiste en determinar el valor de mercado de bienes y servicios entre partes vinculadas considerando el precio o el monto de las contraprestaciones que se hubieran pactado con o entre partes independientes en operaciones comparables. Como se puede observar, según la Ley del Impuesto a la Renta, para determinar el valor de mercado de bienes $y$ servicios, la parte examinada lo puede obtener de dos formas:

1. A través del precio o monto de las contraprestaciones a que se hubieran pactado con partes independientes en operaciones comparables, tal como se sugiere en la figura siguiente para el caso de demostrar el precio Arm's Length para una operación: 


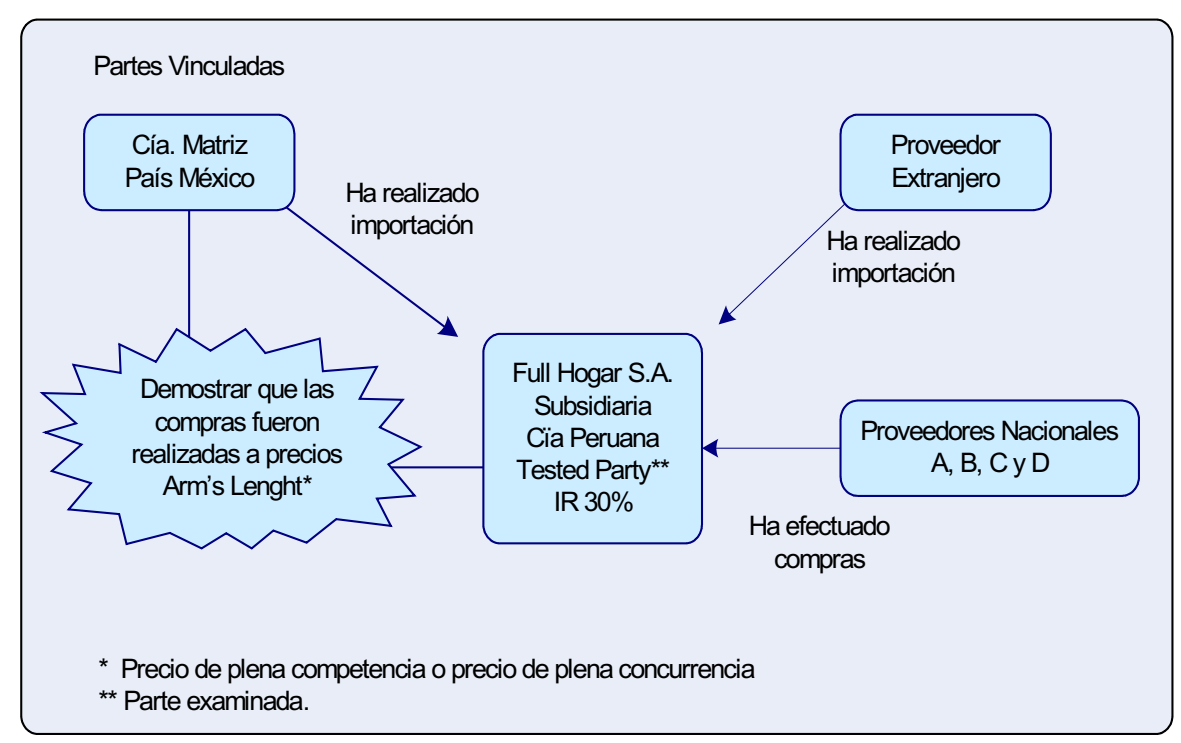

Figura 01

2. O, a través de del precio o monto de las contraprestaciones que se hubieran pactado entre partes independientes en operaciones comparables, tal como se sugiere en la figura siguiente para el caso de demostrar el precio Arm's Length para una operación de venta:

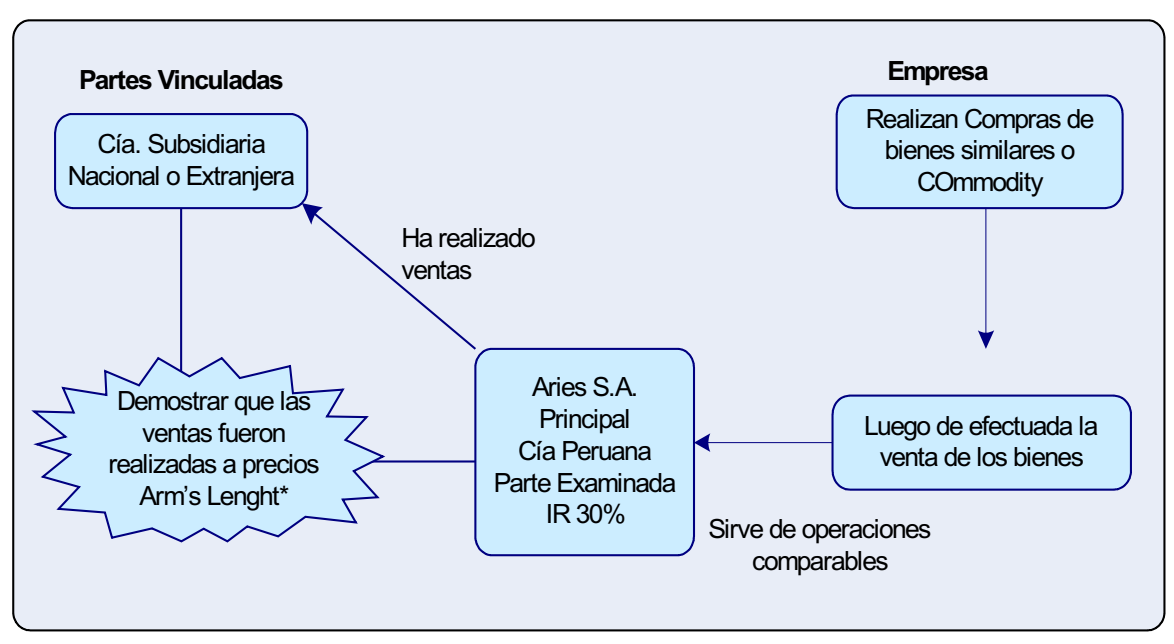

Figura 02 


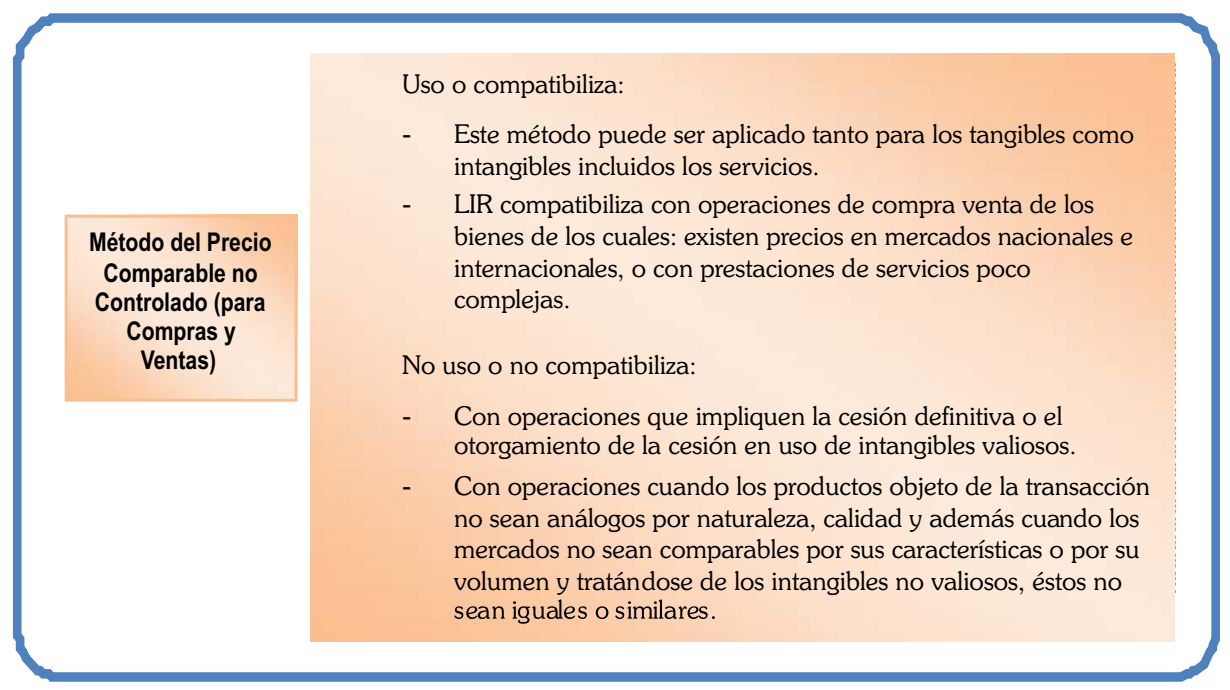

Figura 03. Método del precio comparable.

CASO PRÁCTICO RESUELTO DONDE LOS PRECIOS ARM'S

LENGTH SE HA DETERMINADO POR OPERACIONES

COMPARABLES (VENTAS-COMPRAS) CON PARTES

INDEPENDIENTES. EJERCICIO ECONÓMICO 2011

\section{Empresa subsidiaria importa bienes de su vinculada ubicada en el país de México}

Full Hogar S.A., contribuyente del régimen general, con RUC $\mathrm{N}^{\circ}$ 20020030054, domiciliada en la Av. Pardo $N^{\circ} 1528$ - San Isidro, Lima 27 - Perú, se dedica a la compra venta de artefactos eléctricos para el hogar.

Actualmente, cuenta con más de doce años de experiencia atendiendo al mercado interno a nivel nacional en la modalidad de comercio al por mayor y menor a través de diferentes sucursales, distinguiéndose, no sólo por la calidad de sus productos, sino también por una pronta respuesta a las demandas del mercado de acuerdo con el avance tecnológico.

Full Hogar S.A. es una empresa subsidiaria. La empresa matriz se encuentra ubicada en México. La matriz realiza ventas de artefactos electrodomésticos; también ha efectuado compras a proveedores nacionales y extranjeros, y los precios se mencionan en el cuadro que se detalla en la siguiente figura. 


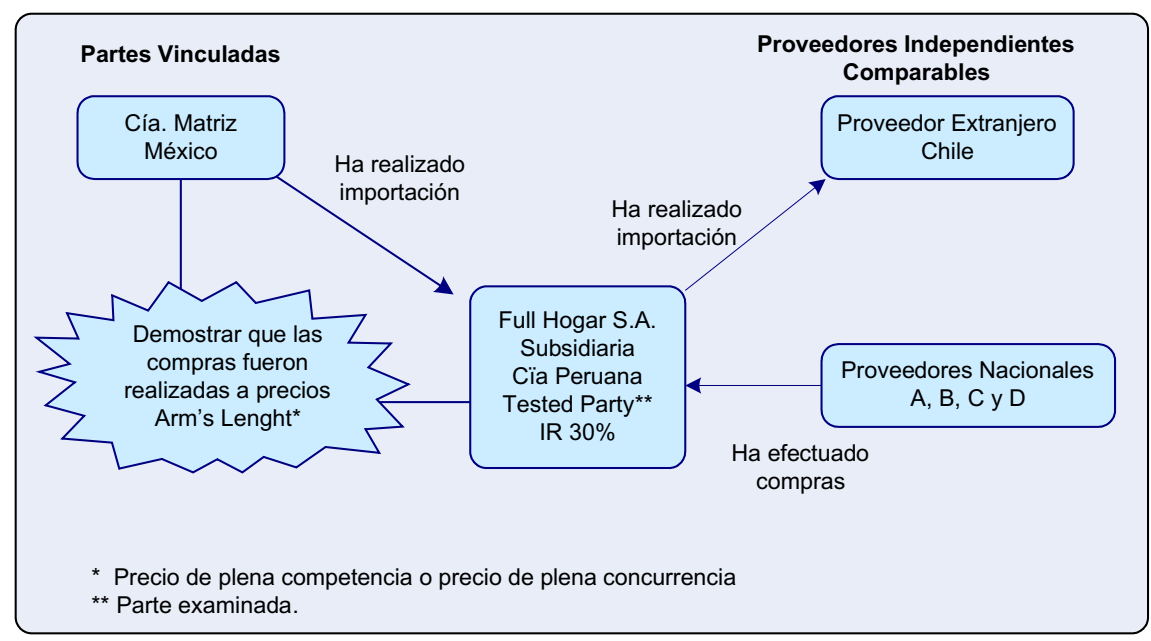

Figura 04

Los precios facturados por la vinculada del exterior, más los gastos de flete, seguro, derechos aduaneros y otros gastos se pueden observar en la tabla siguiente:

Tabla 01

PRECIOS FACTURADOS Y GASTOS

EJERCICIO ECONOMICO 2011

\begin{tabular}{|c|c|c|c|c|c|c|}
\hline Línea de Producto & $\begin{array}{l}\text { Cantidad } \\
\text { Comprada }\end{array}$ & $\begin{array}{l}\text { Valor } \\
\text { FOB }\end{array}$ & $\begin{array}{l}\text { Flete y } \\
\text { seguro }\end{array}$ & $\begin{array}{c}\text { Derechos } \\
\text { aduaneros }\end{array}$ & $\begin{array}{l}\text { Otros } \\
\text { gastos }\end{array}$ & $\begin{array}{l}\text { Costo } \\
\text { total }\end{array}$ \\
\hline \multicolumn{7}{|l|}{ Lavadora Automática } \\
\hline THE ORIGINAL & 450 & $S / 1349.00$ & S/. 67.45 & S/. 113.32 & S/. 13.49 & S/. 1543.26 \\
\hline \multicolumn{7}{|l|}{ Lavadora Automática } \\
\hline SAMSUNG & 380 & 769.00 & 38.45 & 64.60 & 7.69 & 879.74 \\
\hline \multicolumn{7}{|l|}{ Lavadora de Platos } \\
\hline THE ORIGINAL & 520 & 1339.00 & 66.95 & 112.48 & 13.39 & 1531.82 \\
\hline Lavadora DAEWOO & 560 & 639.00 & 31.95 & 53.68 & 6.39 & 731.02 \\
\hline Lavadora SAMSUNG & 320 & 859.00 & 42.95 & 72.16 & 8.59 & 982.70 \\
\hline Refrigeradora LG, & 450 & 1999.00 & 99.95 & 167.92 & 19.99 & 2286.86 \\
\hline Refrigeradora SAMSUNG & 780 & 2399.00 & 119.95 & 201.52 & 23.99 & 2744.46 \\
\hline Refrigeradora FAEOA & 590 & 1499.00 & 74.95 & 125.92 & 14.99 & 1714.86 \\
\hline Refrigeradora DAEWOO & 650 & 999.00 & 49.95 & 83.92 & 9.99 & 1142.86 \\
\hline \multicolumn{7}{|l|}{ Refrigeradora } \\
\hline THE ORIGINAL & 285 & 3359.00 & 167.95 & 282.16 & 33.59 & 3842.70 \\
\hline
\end{tabular}

Fuente: Elaboración Propia. 
Asimismo, la empresa Full Hogar S.A. ha realizado compras a tres proveedores independientes nacionales y a un proveedor no vinculado ubicado en Chile, los precios pagados por dichas adquisiciones se detallan en la tabla siguiente:

Tabla 02

COMPRAS A PROVEEDORES

EJERCICIO ECONOMICO 2011

\begin{tabular}{lrrrr}
\hline Línea de Producto & $\begin{array}{r}\text { Proveedor } \\
\text { Nacional A }\end{array}$ & $\begin{array}{r}\text { Proveedor } \\
\text { Nacional B }\end{array}$ & $\begin{array}{r}\text { Proveedor } \\
\text { Nacional C }\end{array}$ & $\begin{array}{r}\text { Proveedor } \\
\text { de Chile }\end{array}$ \\
\hline Lavadora Automática THE ORIGINAL & S/.1530.00 & S/.1535.00 & S/.1530.00 & S/.1510.00 \\
Lavadora Automática SAMSUNG & 880.00 & 870.00 & 885.00 & 850.00 \\
Lavadora de Platos THE ORIGINAL & 1530.00 & 1520.00 & 1540.00 & 1500.00 \\
Lavadora DAEWO0 & 720.00 & 725.00 & 730.00 & 700.00 \\
Lavadora SAMSUNG & 980.00 & 985.00 & 990.00 & 950.00 \\
Refrigeradora LG & 2300.00 & 2310.00 & 2325.00 & 2290.00 \\
Refrigeradora SAMSUNG & 2750.00 & 2755.00 & 2760.00 & 2710.00 \\
Refrigeradora FAEDA & 1700.00 & 1710.00 & 1720.00 & 1650.00 \\
Refrigeradora DAEW00 & 1120.00 & 1125.00 & 1130.00 & 1100.00 \\
Refrigeradora THE ORIGINAL & 3800.00 & 3820.00 & 3830.00 & 3785.00 \\
\hline
\end{tabular}

Fuente: Elaboración propia.

\section{CÁLCULO DEL RANGO INTERCUARTIL Y MEDIANA}

En el presente caso, los precios pagados por la empresa examinada que se encuentren dentro del cuarto cuartil, éstos deberán ser ajustados por la mediana correspondiente, debido a que en el caso de compras, los precios no deben superar el tercer cuartil para el caso de ventas, los precios no deben estar dentro del primer cuartil, si lo estuvieran deberán ser ajustados por la mediana correspondiente.

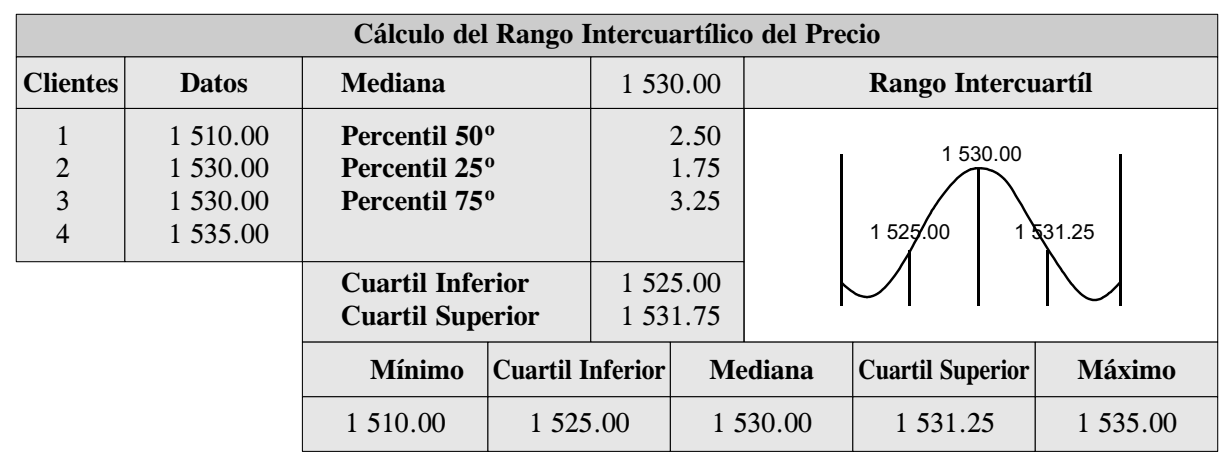


El precio pagado (S/. 1543.26$)$ a la vinculada no se encuentra dentro del rango intercuartil; por tanto, los precios facturados por la vinculada más otros costos están por encima del cuartil superior; en tal sentido, el precio se ajusta por la mediana correspondiente.

\section{Lavadora automática SAMSUNG}

Como se verá en el gráfico siguiente, el precio pagado (S/. 879.74) a la vinculada se encuentra dentro del rango intercuartil; por tanto, los precios facturados por la vinculada más otros costos están a Valores de Mercado.

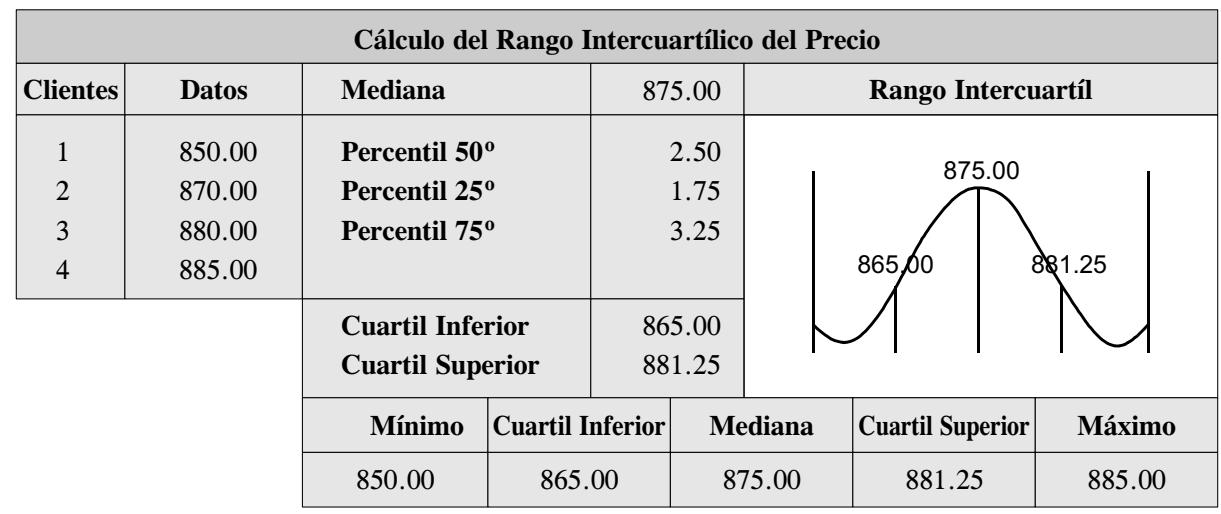

\section{Lavadora de Platos THE ORIGINAL}

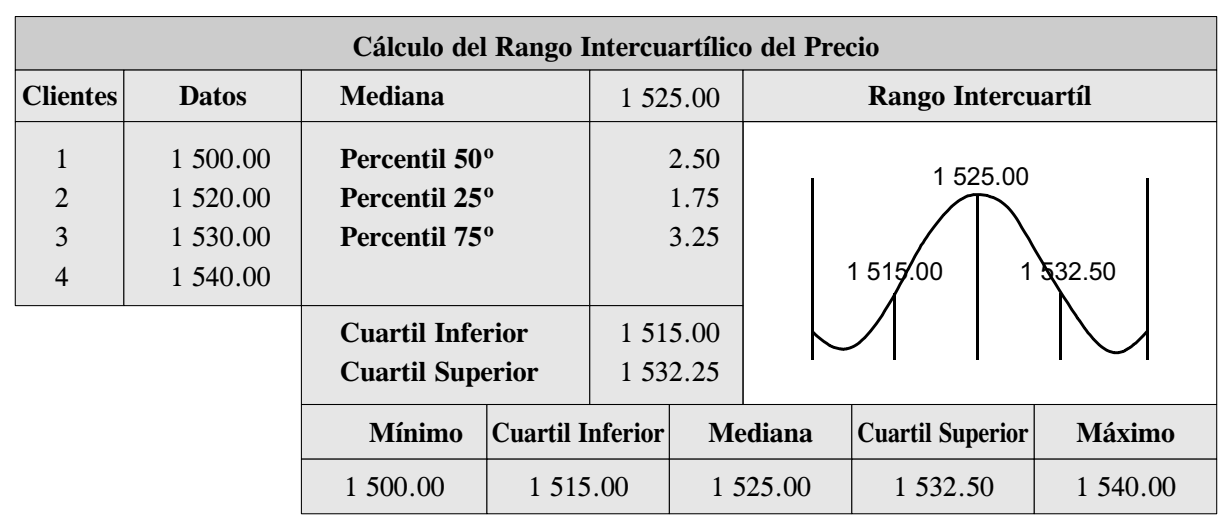

El precio pagado (S/. 1 531.82) a la vinculada se encuentra dentro del rango intercuartil; por tanto, los precios facturados por la vinculada están a valores de mercado. 


\section{Lavadora DAEWOO}

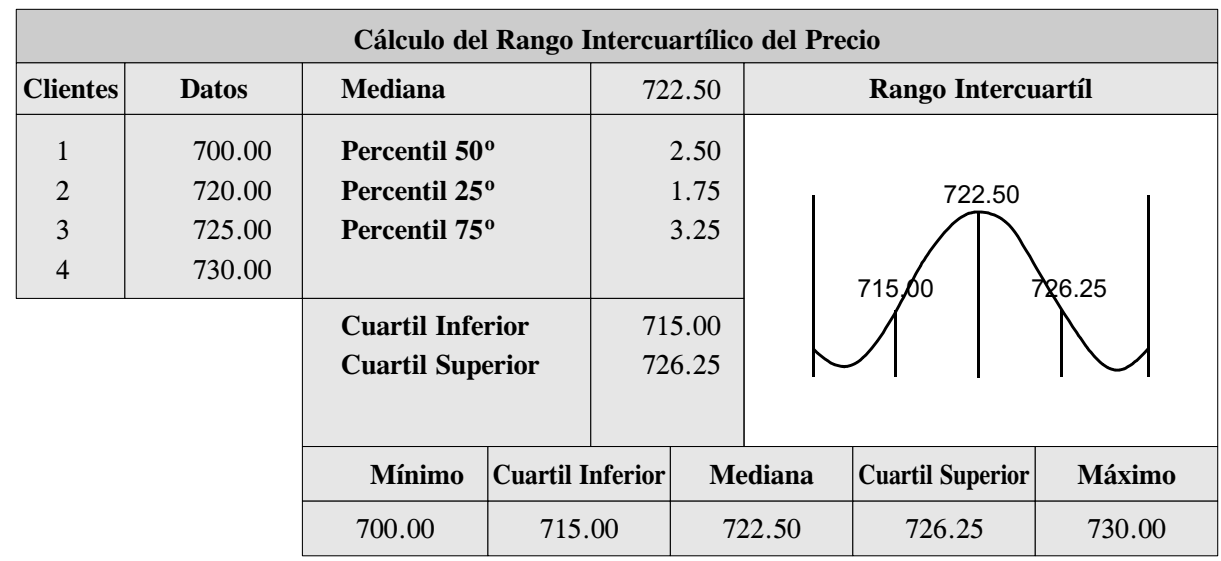

El precio pagado (S/. 731.02) a la vinculada no se encuentra dentro del rango intercuartil; por tanto, los precios facturados por la vinculada más otros costos están por encima del cuartil superior. En tal sentido, el precio se ajusta por la mediana correspondiente.

\section{Lavadora SAMSUNG}

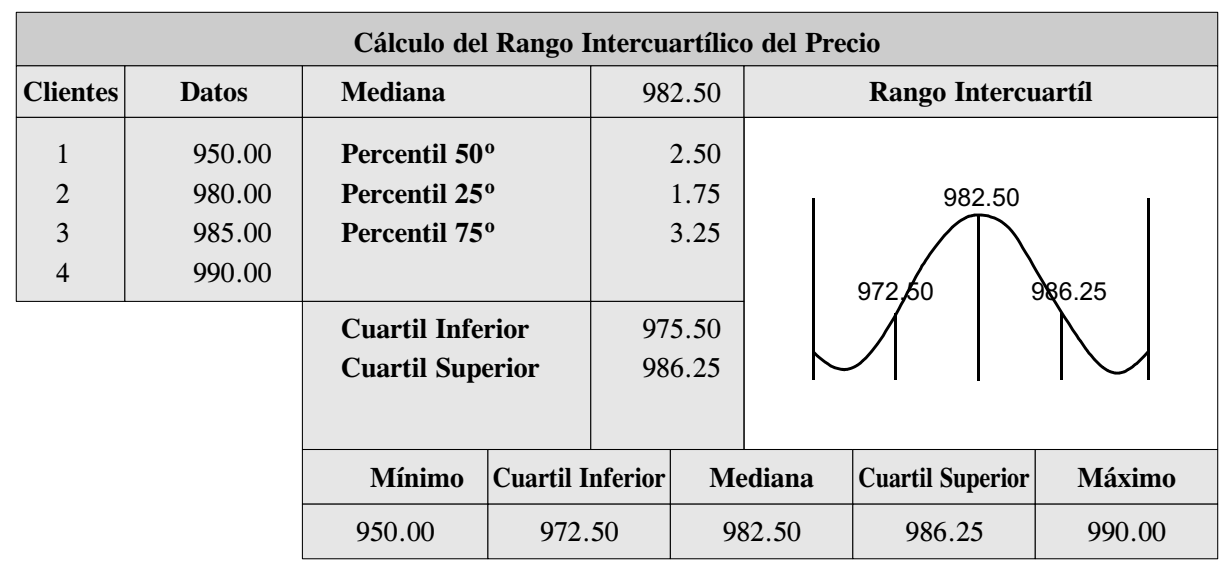

El precio pagado (S/. 982.70) a la vinculada se encuentra dentro del rango intercuartil; por tanto, los precios facturados por la vinculada más otros costos están a valores de mercado. 


\section{Refrigerado LG}

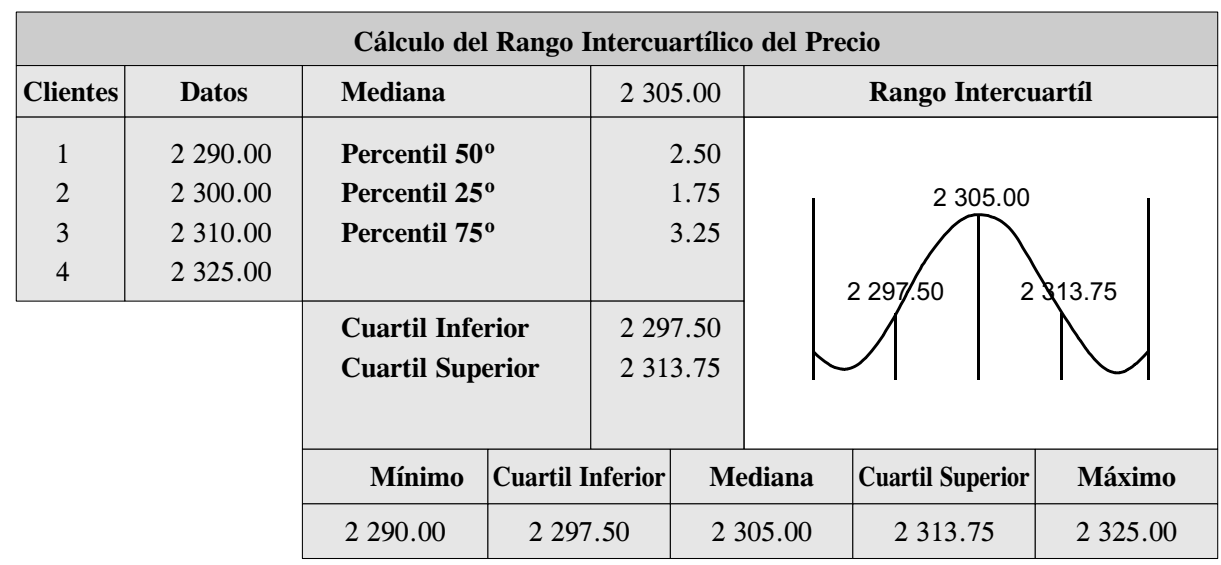

El precio pagado (S/. 2 286.86) a la vinculada no se encuentra dentro del rango intercuartil; por tanto, los precios facturados por la vinculada más otros costos, están por debajo del primer cuartil; en tal sentido, esos precios no se ajustan.

\section{Refrigeradora SAMSUNG}

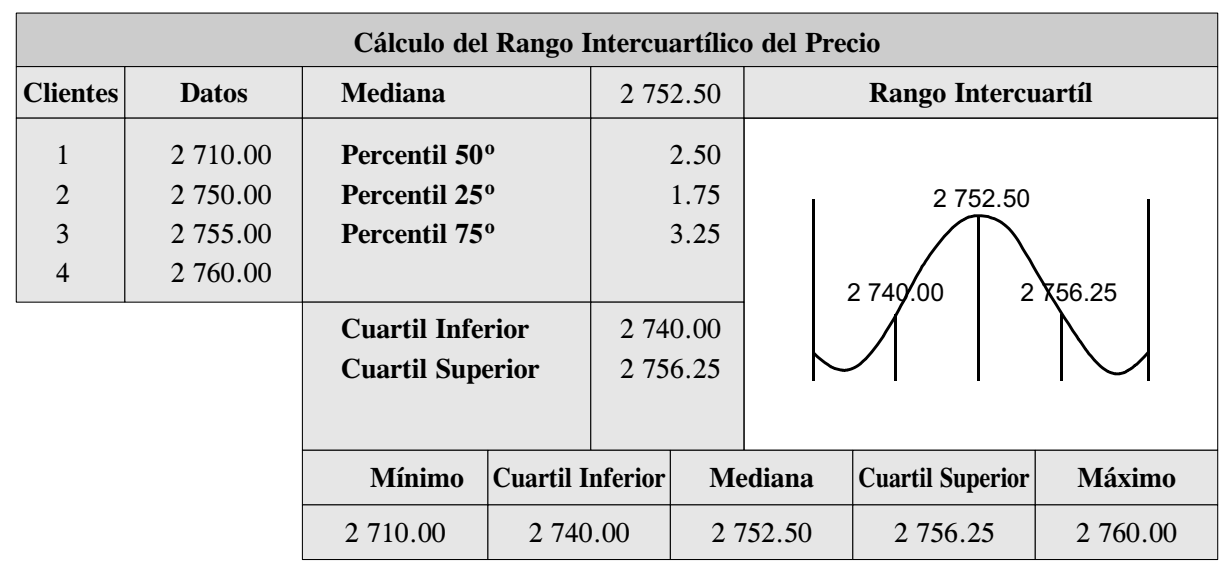

El precio pagado (S/. 2 744.46) a la vinculada se encuentra dentro del rango intercuartil; por tanto, los precios facturados por la vinculada más otros costos, están a valores de mercado. 


\section{Refrigeradora FAEDA}

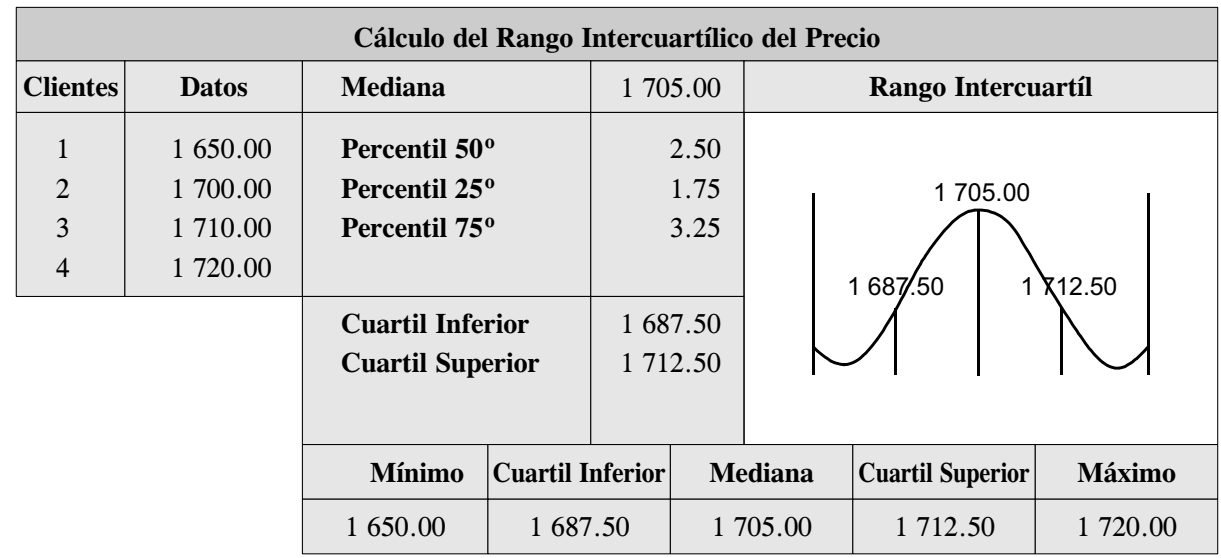

El precio pagado (S/. 1 714.86) a la vinculada no se encuentra dentro del rango intercuartil; por tanto, los precios facturados por la vinculada más otros costos, están por encima del cuartil superior; en tal sentido, el precio se ajusta por la mediana correspondiente.

\section{Refrigeradora DAEWOO}

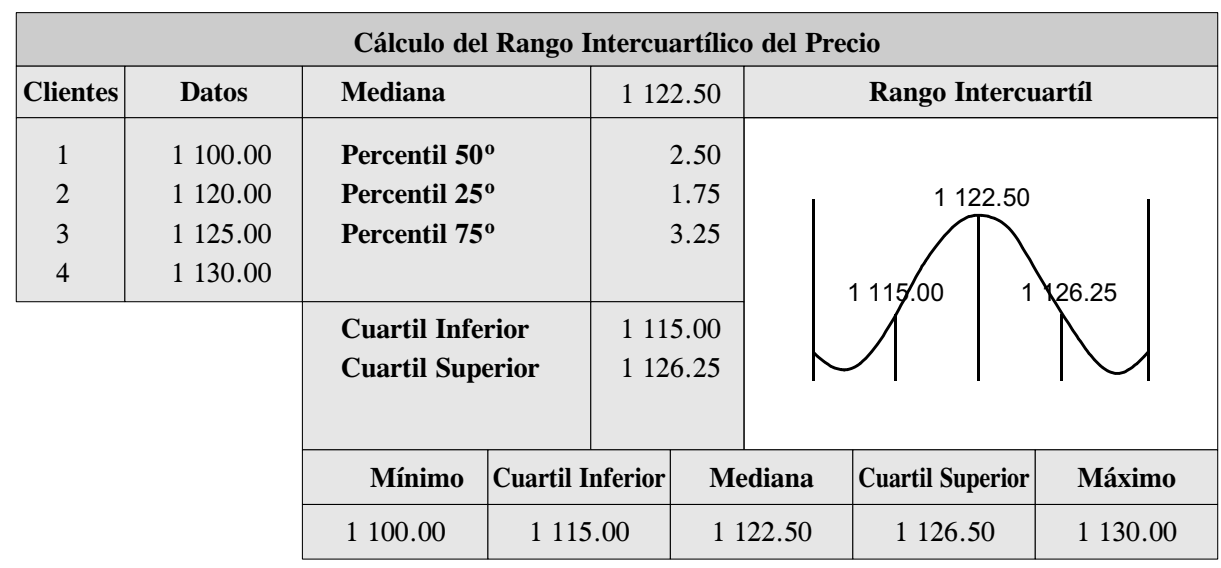

El precio pagado (S/. 1 142.86) a la vinculada no se encuentra dentro del rango intercuartil; por tanto, los precios facturados por la vinculada más otros costos, están por encima del cuartil superior; en tal sentido, el precio se ajusta por la mediana correspondiente. 


\section{Refrigeradora THE ORIGINAL}

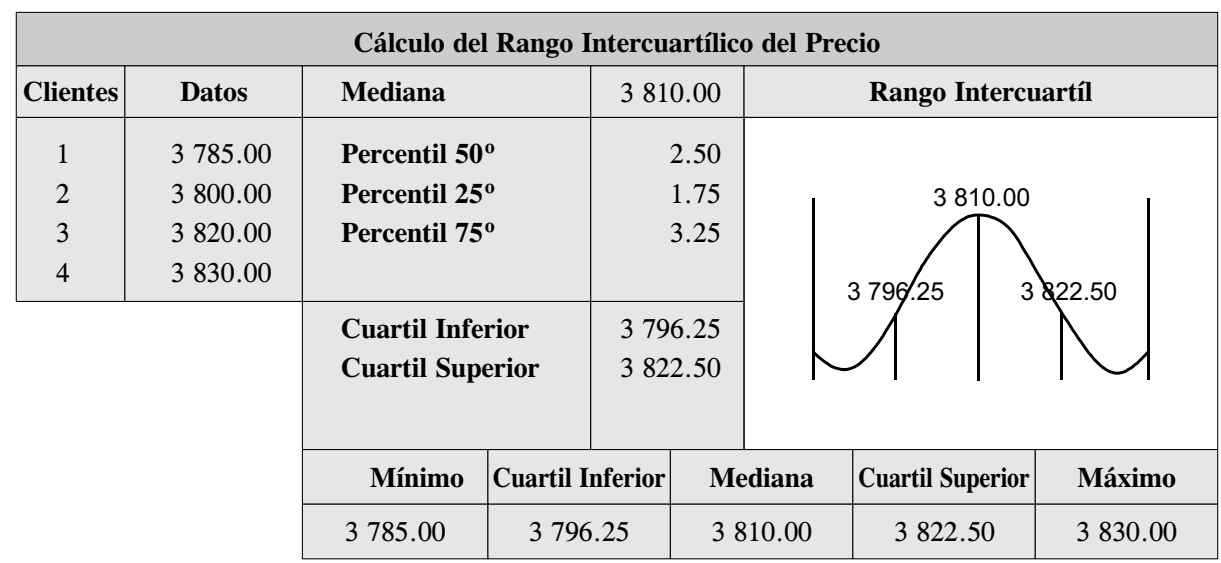

Tabla 03

COMPARACIÓN DE PRECIOS ARM'S

(EJERCICIO ECONÓMICO 2011)

\begin{tabular}{|c|c|c|c|c|c|}
\hline Productos & $\begin{array}{l}\text { V. Compra } \\
\text { según } \\
\text { C. pago }\end{array}$ & $\begin{array}{l}\text { P. Transfer } \\
\text { a Valores } \\
\text { de Mercado }\end{array}$ & $\begin{array}{l}\text { Diferencias } \\
\text { de Precios } \\
\text { V. de Venta }\end{array}$ & $\begin{array}{l}\text { Otros } \\
\text { Gastos }\end{array}$ & $\begin{array}{l}\text { Diferencias } \\
\text { Valor Venta }\end{array}$ \\
\hline \multicolumn{6}{|l|}{ Lavadora Automática } \\
\hline THE ORIGINAL & 1543.26 & 1530,00 & 13.26 & 450 & 5965.20 \\
\hline \multicolumn{6}{|l|}{ Lavadora Automática } \\
\hline SAMSUNG & 879.74 & 879.74 & 0.00 & 380 & 0.00 \\
\hline \multicolumn{6}{|l|}{ Lavadora de Platos } \\
\hline THE ORIGINAL & 1531.82 & 1531.82 & 0.00 & 520 & 0.00 \\
\hline Lavadora DAEWOO & 731.02 & 722.50 & 1.52 & 560 & 4768.96 \\
\hline Lavadora SAMSUNG & 982.70 & 982.70 & 0.00 & 320 & 0.00 \\
\hline Refrigeradora LG & 2286.86 & 2286.86 & 0.00 & 450 & 0.00 \\
\hline Refrigeradora SAMSUNG & 2744.46 & 2744.46 & 0.00 & 780 & 0.00 \\
\hline Refrigeradora FAEDA & 1714.86 & 1705.00 & 9.86 & 590 & 5815.04 \\
\hline Refrigeradora DAEW00 & 1142.86 & 1122.50 & 20.36 & 650 & 13231.40 \\
\hline \multicolumn{6}{|l|}{ Refrigeradora } \\
\hline THE ORIGINAL & 3842.70 & 3810.00 & 32.70 & 285 & 9318.36 \\
\hline \multicolumn{5}{|c|}{ Importe que se debe adicionar a la renta neta imponible } & 39098.96 \\
\hline
\end{tabular}

Fuente: Elaboración propia.

La renta neta imponible de la empresa examinada que se incluyó en la Declaración Jurada Anual del IR por el ejercicio 2011, fue la siguiente: 
La planificación fiscal internacional y su relación con los precios de transferencia...

\begin{tabular}{lcc}
\hline Productos & Tasa IR & S/. \\
\hline $\begin{array}{l}\text { Renta neta imponible } \\
\text { Impuesto a la renta resultante del ejercicio 20X6 }\end{array}$ & $30 \%$ & 3250.960 \\
\hline
\end{tabular}

\section{¿Por qué se debe contar y presentar un Estudio Técnico de Precios de Transferencia?}

El inciso a) del Art. 32-A de la Ley del Impuesto a la Renta, señala que las normas de precios de transferencia serán de aplicación cuando la valoración convenida hubiera determinado un pago del Impuesto a la Renta en el país, inferior al que hubiere correspondido por aplicación del valor de mercado. En el presente caso la empresa examinada está pagando un menor IR; en tal sentido, está obligada a contar con la documentación e información que respalde el cálculo del Estudio Técnico de Precios de Transferencia.

La empresa "Full Hogar S.A." cuenta con la documentación e información detallada por transacción que respalda el cálculo de los precios de transferencia.

Tabla 04

RELIQUIDACIÓN DEL IMPUESTO A LA RENTA

(EJERCICIO ECONÓMICO 2011)

\begin{tabular}{|c|c|c|c|}
\hline $\begin{array}{l}\text { Empresa examinada regulariza } \\
\text { voluntariamente con anterioridad } \\
\text { a cualquier notificación }\end{array}$ & $\begin{array}{l}\text { Según D.J. } \\
\text { Anual } 2011\end{array}$ & $\begin{array}{l}\text { Según D.J. Anual } \\
2011 \text { a V. de } \\
\text { Mercado }\end{array}$ & Diferencias \\
\hline Renta neta imponible & 3250960 & 3290059 & 39099 \\
\hline Impuesto a la Renta $30 \%$ & 975288 & 987018 & 11730 \\
\hline Impuesto a la Renta por regularizar: & & & 11730 \\
\hline $\begin{array}{l}\text { Monto de UIT S/. 3,600 } \\
\text { Multa mínima (5\%) de la UIT* }\end{array}$ & & & 180.00 \\
\hline Numeral 1 Art. 178 del Código Tributario & & $50 \%$ & 5865 \\
\hline $\begin{array}{l}\text { Régimen de gradualidad establecido en } \\
\text { la R.S. N. }{ }^{\circ} \text { 159-2004/SUNA.T }\end{array}$ & & & \\
\hline $\begin{array}{l}\text { Rebaja: Subsana voluntariamente } \\
\text { Inc. a) del art. } 179 \text { del Código Tributario }\end{array}$ & & $90 \%$ & 5279 \\
\hline Multa rebajada & & & 586 \\
\hline
\end{tabular}




\section{¿Por qué se escogió este método?}

Se escogió este método porque las compras de los productos de la empresa peruana a su vinculada de México y a las empresas no vinculadas, ubicadas también en Chile se realizaron en fechas similares, bajo circunstancias análogas. Entonces se puede comparar los precios a los que la empresa peruana compró los productos, tanto a su parte vinculada, como a las empresas no vinculadas.

El reintegro del Impuesto a la Renta y la multa deben ser actualizadas con la tasa de interés moratorio, desde la fecha del vencimiento de la presentación de la Declaración Jurada Anual hasta la fecha de su cancelación. Para tener derecho a la rebaja del $50 \%$ el contribuyente debe cumplir con cancelar la misma. Cabe indicar que el reajuste de la renta neta imponible no modifica la base imponible para los pagos a cuenta del siguiente ejercicio.

\section{DISCUSIÓN}

A pesar del tiempo transcurrido desde la entrada en vigencia de las normas de Precios de Transferencia, aún persiste una serie de dudas en su aplicación. Entre los aspectos no esclarecidos debidamente, son de suma importancia aquéllos referidos al alcance de las obligaciones impuestas a los contribuyentes comprendidos en este régimen.

No se trata solamente de dilucidar cuáles son las obligaciones formales que debe cumplir la empresa, tales como la presentación de la Declaración Jurada Informativa y la elaboración del Estudio de Precios de Transferencia, sino también, entre otros aspectos, determinar la reglas de valoración que se utilizarán y las operaciones a las que se aplicarán.

Es evidente que el artículo $32^{\circ}$ de la Ley del Impuesto a la Renta opera como una norma general, en cuanto establece, además, reglas de valoración. Ciertas transacciones escapan a sus alcances o, en todo caso, serán reguladas, en cuanto a la determinación del valor de mercado, por el Régimen de Precios de Transferencia, aplicable únicamente a las operaciones efectuadas entre partes vinculadas respecto de las cuales se cumplen las condiciones específicamente establecidas en el artículo $32^{\circ}$-A de la Ley del Impuesto a la Renta.

Esta dualidad de sistemas es una de las primeras fuentes de confusión entre los contribuyentes. Es importante, para comprenderla, remontarnos a sus orígenes. 
El régimen previsto en el artículo $32^{\circ}$ de la Ley del Impuesto a la Renta ya se encontraba regulado en forma muy parecida a la actual, aunque referido solamente a las transferencias de propiedad, en el segundo párrafo del artículo $31^{\circ} \mathrm{y}$ en el artículo $32^{\circ}$ del Decreto Legislativo $\mathrm{N}^{\circ} 774$, que aprobó el Texto del Impuesto a la Renta vigente desde el 1 de enero de 1994.

Dada la dificultad existente para establecer los valores de mercado y la falta de preparación de la Superintendencia Nacional de Administración Tributaria en dicha materia, no fue aplicado a menudo en la fiscalización del cumplimiento de las obligaciones tributarias de los contribuyentes. En algunos pocos casos que pueden encontrarse en resoluciones del Tribunal Fiscal, se aprecia que, finalmente, no se terminaba discutiendo sobre valores de mercado, sino sobre una presunción de valor la que, para la Superintendencia Nacional de Administración Tributaria, no admitía prueba en contrario.

Es probablemente debido al reducido control que ejerció la Superintendencia Nacional de Administración Tributaria sobre el cumplimiento de la regla del valor de mercado, que entre los contribuyentes ha existido la idea errada de que su introducción es reciente.

Sólo a partir de la modificación de la Ley del Impuesto a la Renta, establecida en el Decreto Legislativo $\mathrm{N}^{\circ} 945$, se introduce en nuestro país el Régimen de Precios de Transferencia, recogiendo ampliamente en el numeral 4 del artículo $32^{\circ}$ de la Ley del Impuesto a la Renta y artículo $32^{\circ}$-A de la misma, las directrices de la Organización para la Cooperación y Desarrollo Económico sobre la materia.

En este sistema, para establecer el valor de mercado, se compara el precio pactado con el que acordarían empresas independientes que realicen sus transacciones en condiciones iguales o similares. Se utilizan valores comparables internos (ventas a terceros no vinculados realizadas por la misma empresa) o externos (transacciones entre terceros no vinculados), según las circunstancias del caso.

Adicionalmente, para lograr el objetivo de establecer el valor de mercado, se cuenta con los métodos definidos y detallados en las directrices, así como en el mismo artículo $32^{\circ}$-A de la Ley del Impuesto a la Renta, que son clasificados en métodos basados en la transacción (tradicionales) y métodos basados en el beneficio (no tradicionales), y que pueden ser elegidos en función de las circunstancias del caso.

De acuerdo con los datos que contiene la Tabla 01, se tiene información detallada y cuantificable sobre las diferentes líneas de productos, cantidad com- 
parada, valor FOB, cargas directas y el costo total por cada producto elaborado por la empresa Full Hogar S.A.

En la Tabla 02, se consigue información adicional sobre las compras que ha realizado la empresa Full Hogar S.A. a tres proveedores nacionales y a un proveedor que se encuentra en Chile. En dicha tabla se detalla línea de producto y los montos que se han comprado tanto a proveedores nacionales y del exterior (Chile).

Nuestra legislación nacional vigente establece que las empresas industriales o manufactureras deben elaborar un estudio técnico referente a los precios de transferencia para poder demostrar que dichos precios están transados a valores de mercado. Dicha información se encuentra contenida en la Tabla 03 del presente documento de investigación, donde se establece que la empresa Full Hogar S.A., para el ejercicio económico 2011, debe adicionar a la renta neta imponible un importe de S/. 39 098.96.

Finalmente, en la Tabla 04 se presenta la reliquidación del impuesto a la renta correspondiente al ejercicio económico 2011, en donde se encuentra detallada la información que se da en la declaración jurada anual del año 2011, a valor de mercado y las diferencias existentes, para cada rubro, así como las multas y rebajas de acuerdo a lo normado por nuestra ley del impuesto a la renta. Además se puede apreciar que existe diferencias sustanciales en la determinación de renta neta imponible, impuesto a la renta, existiendo S/. 11730 por concepto de impuesto a la renta por regularizar y consecuentemente S/. 586 por multa rebajada, siempre y cuando el contribuyente subsane por voluntad propia las diferencias existentes entre la Declaración Jurada Anual 2011 y la Declaración Jurada Anual a valor de mercado del 2011, mediante la aplicación del principio arm's length, el mismo que regula la determinación del procedimiento del cálculo de los precios de transferencia para empresas vinculadas.

\section{CONCLUSIONES}

1. Las empresas multinacionales que operan en nuestro país, ahora tendrán que replantear el proceso de la planeación de inversiones e incluso revisar el conjunto de todas sus operaciones, en general, para determinar cómo distribuir sus utilidades en sus transacciones intragrupo, a la luz de la legislación vigente, referida a los precios de transferencia.

2. La planificación fiscal internacional, basada en la economía de opción, requiere de una estrategia efectiva y eficiente para maximizar beneficios. 
Para ello acude a las normas tributarias aplicables para obtener la seguridad jurídica en las operaciones comerciales; sin embargo, debe evitar el abuso de estrategias que de manera encubierta y simulada, configuren operaciones entre vinculadas con valores inferiores o mayores, cuya única finalidad sea disminuir la carga fiscal.

3. Los precios de transferencias son instrumento de combate contra el fraude y la evasión, haciendo más transparentes las operaciones de compra y cesión de bienes y servicios entre empresas económicamente vinculadas. De este modo, nuestro país puede incrementar la presión tributaria alcanzando estándares internacionales y consecuentemente, ampliar la base tributaria.

\section{REFERENCIAS BIBLIOGRÁFICAS}

a) Libros:

Adonnino, F. 2008. Estrategias de Planificación Fiscal Internacional. Editorial Gaceta Fiscal. España.

ApaZA, M. 2007. Precios de transferencia en el Perú. Editorial Veritas. Lima, Perú.

ARESPACOChagA, J. 2004. Planificación Fiscal Internacional, Editorial Marcial Pons. Madrid España.

BARNADAS, W. 2009. Elusión y Evasión Fiscal. Editorial Uteha. España.

CARrión, H. 2005. El Problema de la Transferencia de Beneficios. Editorial Pearson. D.F. México.

GARCíA, F. 2009. Planificación Fiscal Internacional. Uteha, México D.F.

GuíA DE LA OCDE 1999. Directrices Aplicables en Materia de Precios de Transferencia a Empresas Multinacionales y Administraciones Tributarias. s/pi.

SANMARCO, J. 2008. Régimen de Precios de Transferencia. Editorial Universo. España.

SPITZ, B. 2006. Planificación Fiscal Internacional. Editorial Deusto. Bilbao - España.

b) Normas Legales:

LEY N ${ }^{\circ}$ 27356: Impuesto a la Renta (18.10.00).

D.S. No 045-01-EF: Reglamento del Impuesto a la renta (20.03.01).

D. LegisLativo $\mathrm{N}^{\circ}$ 945: Modificaciones de la Ley del Impuesto a la Renta (22.12.03).

DECRETo SuPREMo No 179-2004-EF: Texto Único Ordenado de la Ley del Impuesto a la Renta (08.12.04).

DeCRETO SuPREMo No $190-2005$-EF: Modifican Reglamento de la Ley del Impuesto a la Renta (31.12.05).

RESOLUCIÓN DE SUPERINTENDENCIA N ${ }^{\circ}$ 167-2006/SUNAT. Norma que establece excepciones a la obligación de presentar declaración jurada anual informativa; y de contar con estudio técnico de precios de transferencia (14.10.06).

RESOLUCIÓN DE SUPERINTENDENCIA N ${ }^{\circ} 008-2007 /$ SUNAT. Norma que amplía excepciones a la obligación de contar con estudio técnico de precios de transferencia (07.01.07). 
RESOLUCIÓN DE SUPERINTENDENCIA No 061 -2007/SUNAT. Aprueban disposiciones y formulario para la presentación de la Declaración Jurada Anual Informativa de Precios de Transferencia (30.03.07).

RESOLUCIÓN DE SUPERINTENDENCIA N 140-2007/SUNAT. Prorrogan plazo para presentar la declaración jurada anual informativa de precios de transferencia correspondiente al ejercicio 2006 (04.07.07).

RESOLUCIÓN DE SUPERINTENDENCIA N ${ }^{\circ}$ 171-2007/SUNAT. Prorrogan plazo para presentar la declaración jurada anual informativa de precios de transferencia correspondiente al ejercicio 2006 (08.09.07).

RESOLUCIÓN DE SUPERINTENDENCIA N ${ }^{\circ}$ 086-2008/SUNAT. Modifican la Resolución de Superintendencia $\mathrm{N}^{\circ}$ 167-2006/SUNAT a efectos de facilitar el cumplimiento de las obligaciones formales previstas en las normas sobre Precios de Transferencia (31.05.08).

RESOLUCIÓN DE SUPERINTENDENCIA $\mathrm{N}^{\circ}$ 087-2008/SUNAT. Aprueban disposiciones $\mathrm{y}$ Formulario para la presentación de la Declaración Jurada Anual Informativa de Precios de Transferencia (31.05.08).

RESOLUCIÓN DE SUPERINTENDENCIA N $\mathrm{N}^{\circ}$ 169-2009/SUNAT. Aprueban disposiciones y Formulario para la presentación de la Declaración Jurada Anual Informativa de Precios de Transferencia correspondiente al ejercicio 2008 (08.08.09).

RESOLUCIÓN DE SUPERINTENDENCIA N ${ }^{\circ}$ 200-2010/SUNAT. Establecen plazos para Declaración Jurada Anual Informativa de los Precios de Transferencias (06.09.10).

RESOlUCIÓN DE SUPERINTENDENCIA N ${ }^{\circ} 14-2011 /$ SUNAT. Modificar Art. $5^{\circ}$ de la Resolución de Superintendencia N ${ }^{\circ} 167-2006 /$ SUNAT (10.05.11). 